\title{
Passivo ambiental: revisão teórica de custos na indústria do petróleo
}

\author{
Carlos Alberto Bezerra Galdino \\ Mestrando do Programa de Engenharia de produção - PEP/UFRN \\ E-mail:galdino6@ig.com.br \\ Esmeraldo Macêdo Dos Santos \\ Mestrando do Programa de Engenharia de produção - PEP/UFRN \\ E-mail: esmeraldomacedo@yahoo.com \\ José IVAm Pinheiro \\ Mestrando do Programa de Engenharia de produção - PEP/UFRN \\ E-mail:ivampinheiro@yahoo.com.br \\ Sérgio Marques JúnIOR \\ Prof. Dr. do Programa de Engenharia de produção - PEP/UFRN \\ E-mail:sergio@ct.ufrn.br \\ Rubens Eugênio Barreto Ramos \\ Prof. Dr. do Programa de Engenharia de produção - PEP/UFRN
}

E-mail: rubens@ct.ufrn.br

\section{Resumo}

O objetivo deste trabalho é apresentar uma revisão teórica sobre o passivo ambiental para uso de gestores públicos ou privados, bem como de pesquisadores no setor de exploração de petróleo. Essa revisão, além de apresentar uma definição de passivo ambiental, também define os tipos e técnicas de passivo coletadas pela Agência de Proteção Ambiental Americana (EPA), técnicas essas que objetivam a estimação de diversos tipos de custos ambientais, decorrentes de atividades passadas ou presentes, da produção de bens que causaram ou, provavelmente, venham a causar danos ao meio ambiente e, conseqüentemente, algumas implicações de natureza legal, econômica e social.

\section{Palavras-chave}

Passivo ambiental, estratégia ambiental, gestão ambiental.

\section{Environmental liabilities: theoretical revision of costs in the industry of the oil}

\begin{abstract}
The objective of this work is to present a theoretical revision on the environmental liabilities for use of public or private managers, as well as of researchers in the sector of oil exploration. This revision, besides presenting a definition of environmental liabilities, also defines the types and techniques of liabilities collected by the U.S. Environmental Protection Agency (EPA), which aim the estimation of different types of ambient costs, resulting from past or present activities, of the production of goods that caused or, will probably, come to cause damages to the environment and, consequently, some implications of legal, economic and social nature.
\end{abstract}

\section{Key words}

Environmental liability, environmental strategy, environmental management. 


\section{INTRODUĈ̣̃O}

As questões ambientais assumem um importante papel no valor da propriedade, valor esse relacionado principalmente ao nível de consciência do mercado quanto ao potencial de poluições químicas, radiativas, sonoras e outros poluentes das diversas atividades industriais que contaminam o solo, o ar, os rios e os lençóis freáticos.

Nos Estados Unidos, várias empresas estão diminuindo suas atividades produtivas, não só devido à curta margem de lucros imposta pela competição internacional, mas também por força das regulamentações ambientais (PHILLIPS, 2002). O desenvolvimento econômico defronta-se com a polêmica questão ambiental nos países que formam a União Européia, o que mostra o nível de consciência ambiental dos empresários. Um bom exemplo disso é a contaminação do solo, que tem sido aceita como uma conseqüência inevitável da industrialização européia (HOLLINS; PERCY, 1998). No entanto, quando o solo é contaminado, o valor de mercado da propriedade é afetado, gerando-se passivo ambiental. Os custos de limpeza, as altas penalidades e multas impostas pelas violações ambientais estão deixando as pessoas mais preocupadas e atentas para os perigos que poderão expôlas ao passivo. Estima-se que no Brasil podem existir mais de 20 milhões de toneladas de resíduos industriais perigosos em situação de se tornarem passivos ambientais (ÁVILA, 2002).

O setor de exploração de petróleo é altamente influenciado pelas questões ambientais. Acidentes como o do Exxon Valdez e o caso da Petrobrás em janeiro de 2000, em que houve um vazamento de milhares de litros no mar da Bahia de Guanabara, são exemplos que ampliam o debate relativo à necessidade de se estimar o passivo ambiental das organizações. Como exemplo, nos Estados Unidos discute-se uma política com modelos socialmente aceitos para impor limites no passivo ambiental por danos causados pela poluição do óleo (JIN, 2002). Em empreendimentos que envolvem riscos, há a obrigatoriedade legal de estudos de impactos ambientais que objetivam caracterizar o empreendimento e o meio ambiente que o cerca, avaliando os impactos causados nos meios físicos, bióticos e socioeconômicos (RIBEIRO; SOUZA, 2003). As empresas que lidam com produtos perigosos precisam conhecer os procedimentos necessários para estimar o passivo ambiental - caso ele exista - para contabilizar como depreciação do valor da empresa, bem como fazer estimativas para serem usadas como fundo de reserva para cobrir custos em prováveis danos que possam causar ao meio ambiente em caso de acidente.

O passivo ambiental associado à atividade de exploração de petróleo gera uma série de questões que orientam o desenvolvimento de procedimentos direcionados à busca de uma gestão de problemas ambientais que integrem fatores econômicos, sociais, políticos e ideológicos. Assim, espera-se que este trabalho possa contribuir como mais uma referência em estudos de pesquisadores que trabalham para um desenvolvimento que favoreça o equilíbrio entre o meio ambiente e a indústria do petróleo. Dessa forma, o objetivo do presente trabalho é apresentar uma revisão teórica referente aos modelos de estimativa do passivo ambiental das organizações, de forma a despertar interesse de gestores de organizações públicas e privadas, assim como pesquisadores no setor de exploração de petróleo.

\section{DEFINICCÃO DE PASSIVO AMBIENTAL}

O termo "passivo ambiental" causa muitas discussões por estar freqüentemente ligado a multas, penalidades ou violações a leis ambientais. É muito comum a associação entre custos e o cumprimento de regulamentações. Apesar de ser um termo abrangente, pode-se definir passivo ambiental como uma obrigação adquirida em decorrência de transações anteriores ou presentes, que provocaram ou provocam danos ao meio ambiente ou a terceiros, de forma voluntária ou involuntária, os quais deverão ser indenizados através da entrega de benefícios econômicos ou prestação de serviços em um momento futuro (EPA, 1996; RIBEIRO, 2000; GALDINO et al., 2002).

O passivo ambiental está presente nas empresas através dos riscos do negócio que podem ser revelados através de situações como: por iniciativa da empresa que reconhece suas obrigações, antecipando as ações de terceiros; por reivindicação de terceiros, em que são requeridos pela comunidade em decorrência de prejuízos sofridos em função das atividades operacionais; e, finalmente, por exigibilidade das obrigações ambientais, cujos órgãos ambientais aplicam penalidades ao verificar o grau de responsabilidade da empresa. Os danos podem ser mitigados em forma de empréstimos a bancos para investimento em gestão ambiental na empresa, compra de tecnologias limpas, pagamento de multas decorrentes de infração ambiental, remuneração de mão-de-obra especializada em gestão ambiental, indenizações ambientais à sociedade ou através de investimento do lucro da entidade em programas sociais, entre outros. Para Antonius (1999), o gerenciamento ambiental de uma indústria pode ser conceituado como a integração de sistemas e programas organizacionais que permitem:

- O controle e a redução dos impactos ao meio ambiente;

- O cumprimento de leis e normas ambientais;

- O desenvolvimento e uso de tecnologias ambientais que eliminem resíduos nas indústrias, bem como a diminui- 
ção com os gastos de energia e materiais;

- A avaliação dos processos e parâmetros ambientais;

- A eliminação e/ou redução dos riscos ao meio ambiente e ao homem;

- Um melhor relacionamento entre a comunidade e o governo;

- A antecipação de questões ambientais que evitem danos ao meio ambiente e, particularmente, à saúde humana.

Adotar as recomendações do sistema de gestão ambiental facilita a avaliação do passivo ambiental e melhora a imagem da corporação, pois esse procedimento já é usado nas estratégias das empresas globalizadas. As empresas que adotam mecanismos de preservação do meio ambiente estão valorizando as suas marcas frente à sociedade e podem favorecer a expansão da empresa no comércio internacional - o qual é cercado de grandes exigências ambientais - tornando-as conhecidas como empresas socialmente responsáveis. Por outro lado, ficar alheio à questão ambiental também passa a ser uma atitude que pode refletir como uma rotulagem negativa para a empresa. Esse tipo de resistência dos empresários em reconhecer e assumir suas responsabilidades perante a sociedade tem sido uma das principais barreiras para os profissionais que procuram solucionar problemas relativos ao meio ambiente.

\section{IDENTIFICAC̣̃̃O DO PASSIVO AMBIENTAL}

Segundo Carvalho; Ribeiro (2000), "os passivos ambientais devem ser reconhecidos e contabilizados no momento em que acontecem seus fatores geradores, ou em situações extremas, a partir do simples conhecimento de sua existência potencial".

O desenvolvimento de um sistema contábil de custos ambientais depende da cultura da corporação que está mudando. Os empresários que resistiram durante vários anos a fazer investimentos na área ambiental, por acreditar que tais investimentos reduziriam o resultado da empresa, hoje percebem que a falta de investimentos na área pode comprometer a continuidade da empresa. Entretanto, as empresas que possuem passivos ambientais que não se encontram identificados, dificilmente terão subsídios para uma correta e real avaliação da situação da empresa e, conseqüentemente, não poderão julgar a viabilidade de fazerem investimentos na instituição (RIBEIRO; SOUSA, 2003).

Segundo Ribeiro; Lisboa (2000), as informações contidas no EIA - Estudo de Impacto Ambiental - e no RIMA - Relatório de Impacto ao Meio Ambiente servem como uma das formas possíveis para se identificar o passivo ambiental.

\section{IMPLICAC̣ÕES LEGAIS DO PASSIVO AMBIENTAL}

O passivo ambiental insere-se no âmbito social por se tratar de uma exigência legal que responsabiliza o autor do dano a reparar ou mitigar prejuízos de cunho social ou privado, provocados direta ou indiretamente através das externalidades provocadas no meio ambiente (EPA, 1996).

Segundo Claro (2001), três grupos de fatores influenciam nas práticas ambientais de uma empresa: a regulamentação pública, as pressões exercidas pela sociedade e as pressões exercidas pelas relações entre empresas e entre empresas e consumidores. A maioria das empresas, de acordo com Claro (2001), adota estratégias ambientais em função do risco de multa, buscando apenas sua conformidade com a legislação ambiental.

Uma organização internacional ou nacional que pretende adquirir uma propriedade deverá levar em conta a existência de passivos, pois esses podem ser herdados após a compra do bem. Da mesma forma, empresas que desenvolvem projetos ou aplicam dinheiro em um negócio também precisam estar cientes, pois podem sofrer prejuízos no futuro. Nos Estados Unidos, desde 1980, a pessoa ou instituição que empresta dinheiro deve assegurar a dívida por custos de limpeza ambiental por estar de acordo com o avaliado (proprietário ou responsável pela execução do negócio financiado), ou talvez mais significativamente por ter o poder de evitar os danos que o mutuário venha a executar (HOLLINS; PERCY, 1998).

No Brasil, as leis ambientais estão cada vez mais conhecidas e aplicadas para os danos causados ao meio ambiente. A Lei 6.938, de 31 de agosto de 1981, que dispõe sobre a Política Nacional do Meio Ambiente, dá uma ampla definição no artigo $3^{\text {o }}$ sobre a poluição: "A degradação da qualidade ambiental resultante de atividades que, direta ou indiretamente:

a) Prejudiquem a saúde, a segurança e o bem-estar da população;

b) Criem condições adversas às atividades sociais e econômicas;

c) Afetem desfavoravelmente a biota;

d) Afetem condições estéticas ou sanitárias do meio ambiente;

e) Lancem matérias ou energia em desacordo com os padrões ambientais estabelecidos".

A empresa que provocar qualquer uma das degradações acima citadas está passível de sofrer algumas restrições como dispõe a Lei 9.605, de fevereiro de 1998, sobre as sanções penais e administrativas derivadas de condutas e atividades lesivas ao meio ambiente. No artigo $8^{\circ}$ dessa lei aplicam-se algumas penas restritivas: 
I - prestação de serviços à comunidade;

II - interdição temporária de direitos;

III - suspensão parcial ou total das atividades;

IV - prestação pecuniária;

$\mathrm{V}$ - recolhimento domiciliar.

Além das multas que a empresa poderá sofrer, corre o risco de perder profissionais importantes para a condução do processo operacional durante uma interdição temporária, bem como perder seus clientes e contrair uma dívida com os fornecedores. Daí a importância de se conhecer uma real situação do passivo ambiental gerado ao longo de sua trajetória, para que de forma espontânea a empresa possa fazer um planejamento, a fim de corrigir qualquer dano que possa ter causado ao meio ambiente (GALDINO et al., 2002).

Tornar o setor de petróleo mais competitivo e dinâmico no Brasil, possibilitando o investimento de empresas privadas no setor petrolífero, foi o propósito da criação da Agência Nacional de Petróleo (ANP), através da Lei 9.487/97. Coube, assim, à ANP o papel de reguladora e ao Conselho Nacional de Política Energética (CNPE) a atribuição de assessorar a Presidência da República na formulação de políticas e diretrizes para o setor energético brasileiro. Ambos são vinculados ao Ministério de Minas e Energia (MME), (MACHADO, 2002).

O termo "passivo" é citado no contrato de concessão para exploração, desenvolvimento e produção de petróleo e gás natural da ANP, Cláusula Décima-Oitava, parágrafo 18.5.1, que trata dos Bens e afirma que a devolução da Área de Concessão não exime o Concessionário do cumprimento de todas as obrigações pendentes, nem da responsabilidade pelos passivos, irregularidades ou infrações constatadas a posteriori, de acordo com a legislação aplicável. Quanto aos recursos naturais especificamente, a Cláusula Vigésima-Primeira que trata do Meio Ambiente, mas especificamente no parágrafo 21.1, dis- põe que o Concessionário adotará, por sua conta e risco, todas as medidas necessárias para a conservação dos reservatórios e dos outros recursos naturais para a proteção do ar, do solo e da água de superfície ou da subterrânea, sujeitando-se à legislação e regulamentação brasileiras sobre o meio ambiente e, na sua ausência ou lacuna, adotando as melhores práticas da indústria do petróleo a respeito.

O Contrato de Concessão dispõe de outros parágrafos que abordam tanto o controle ambiental como as responsabilidades por danos e prejuízos causados ao meio ambiente e a terceiros. Na realidade, a ANP apenas reforça as obrigações das concessionárias por qualquer dano, como foi explicitado pela Política Nacional do Meio Ambiente.

\section{IMPACTOS AMBIENTAIS NA INDÚSTRIA DO PETRÓLEO}

A Indústria do Petróleo se enquadra no modelo de instituição que deveria implementar o Passivo Ambiental como mais uma ferramenta no seu Sistema de Gestão Ambiental. De acordo com o relatório da Petrobrás (2001), a companhia está sujeita a diversas leis e normas ambientais que disciplinam a descarga de petróleo, gás e outros materiais. Além disso, reconhece que os efeitos das operações da companhia sobre o meio ambiente devem ser por ela corrigidos ou mitigados. O quadro abaixo ilustra alguns acidentes ocorridos no Brasil.

O petróleo é uma fonte energética que causa um dos maiores impactos ao longo de todo o seu ciclo de vida, que vai desde a extração até o consumo final (como as emissões dos veículos e as atividades industriais). Segundo Azuaga (2000), a trajetória do petróleo no Brasil possui quatro cadeias básicas: extração, transporte, armazenamento e refino.

Quadro 1: Dificuldades do programa de desenvolvimento e soluções propostas.

\begin{tabular}{|l|l|}
\hline \multicolumn{1}{|c|}{ DATA } & \multicolumn{1}{c|}{ ACIDENTE } \\
\hline Outubro/2001 & Vazamento de 392 mil litros de nafta no mar, na saída do porto de Paranaguá. \\
\hline Março/2001 & $\begin{array}{l}\text { Explosão ocorrida na plataforma P-36, que causou derramamento de 78.400 barris de óleo } \\
\text { diesel e petróleo bruto no Paraná. }\end{array}$ \\
\hline Fevereiro/2001 & Rompimento de oleoduto e derramamento de 340 barris de óleo de combustível no Paraná. \\
\hline Janeiro/2000 & Vazamento de óleo na Baía de Guanabara. \\
\hline Julho/2000 & Vazamento de óleo na Refinaria Presidente Vargas. \\
\hline
\end{tabular}

Fonte: Petrobrás (2001) 
A não-implementação das normalizações ambientais impõe, além de multas elevadas, o dever de reparar os danos causados ao meio ambiente. A imposição dessas normas tem impulsionado a prevenção de acidentes ambientais e, conseqüentemente, evitado grandes prejuízos com multas e indenizações de passivos ambientais.

A Petrobrás criou o Programa de Excelência em Gestão Ambiental e Segurança Operacional (PÉGASO). Esse programa atua nas áreas de prevenção, contingência, resíduos, efluentes, emissões, gestão, relacionamento com a sociedade e segurança no trabalho. O referido programa já recebeu 1,95 bilhão - de 2000 a 2001 - e tem uma previsão de até 2003 ter integralizado 3,2 bilhões. Ainda no que se refere à segurança, meio ambiente e saúde, a Petrobrás está implementando um ambicioso programa que visa adequá-la aos padrões internacionais até o ano de 2005 (PETROBRÁS, 2001).

Segundo Ribeiro; Souza (2003), apesar dos investimentos feitos pela Petrobrás através de medidas preventivas, gerenciais, emergenciais, entre outras, os acidentes ainda continuam ocorrendo. Os investimentos em meio ambiente na área de passivo ambiental ainda são insuficientes e tendem a crescer devido às exigências da sociedade e do próprio mercado frente aos problemas existentes.

\section{MODELOS DE AVALIAC̣ÃO DE PASSIVO AMBIENTAL}

Segundo Ribeiro; Souza (2003), a contabilidade permite a cada grupo de usuários avaliar a situação econômica e financeira de uma entidade, bem como possibilita demonstrar a situação ambiental da empresa. Como exemplo, os referidos autores citam os impactos ambientais em que a Petrobrás esteve envolvida e como ela vem agindo para prevenir os acidentes e diminuir os efeitos em caso da impossibilidade de evitá-los.

A Environmental Protection Agency (EPA) é uma agência americana que reuniu documentos de uma variedade de técnicas para estimar o passivo ambiental (environmental liability), obtidas através de contatos com profissionais de indústrias, de órgãos governamentais, de academias, e através de revistas de contabilidade ambiental. Abaixo estão relacionados alguns procedimentos coletados inteiramente de trabalhos da EPA (1996), que reuniu alguns tipos de passivos ambientais como:

- Conformidades - são obrigações relacionadas às leis e regulamentações aplicadas à produção, ao uso, disposição, lançamentos de substâncias químicas e outras atividades que afetam o meio ambiente. Nos planos de negócios, algumas companhias podem considerar a possibilidade de novas leis que, porventura, possam ser decreta- das. Adicionalmente, as empresas podem descobrir se elas estão ou não em conformidade com as leis e regulamentações existentes. Os custos de conformidades podem ser gastos modestos como requerimento administrativo de conformidade (elaboração de relatório para prestação de contas, treinamentos), ou gastos substanciais e custos (tratamento de resíduos lançados em terra ou na água, contenção de derramamento ou limpeza das emissões de poluentes no ar).

- Remediações - são obrigações já existentes ou passíveis de ocorrência relacionadas a uma contaminação provocada. Algumas vezes têm sido decretados requerimentos para limpeza de propriedade como parte de programas regulatórios, ou seja, instrumentos obrigatórios para uma empresa operar, como, por exemplo, o EIA. É fácil velar a distinção entre fechar por obrigações rotineiras de conformidades e o fim de vida útil por aparatos e obrigação de remediação, para limpar a poluição que coloca em posição de risco a saúde do meio ambiente. Manter o compromisso de atualizar as conformidades ambientais pode ajudar a minimizar futuras obrigações com esse tipo de passivo, o qual tende a ser muito caro, pois pode incluir escavação, perfuração, construção, extração, tratamento de solo e água, inspeção e também custos com agências reguladoras. $\mathrm{O}$ custo de uma remediação pode incluir, por exemplo, uma provisão de suprimentos de água potável para residências de uma comunidade afetada e, em algumas circunstâncias, compras de propriedades e despesas com mudanças.

- Multas e penalidades - são obrigações para pagamento de multas e penalidades estabelecidas por lei. As companhias que não estão em conformidade com os regulamentos aplicáveis estão sujeitas a multas e/ou custos de projetos de revitalização ambiental. Esse tipo de passivo pode variar desde valores modestos a grandes quantias em dinheiro. Geralmente, uma penalidade civil é estimada, pelo menos, em consonância com os custos equivalentes ao que a companhia deixou de investir em conformidades por ignorar as leis.

- Compensações - são obrigações para compensar pessoas ou propriedades por danos causados. De acordo com algumas leis, uma companhia pode ser obrigada a compensar pessoas por danos provocados a elas, as suas propriedades e seus negócios por uso ou lançamentos de substâncias tóxicas ou outros poluentes. Esse passivo pode ocorrer quando uma companhia não atende a todos os padrões ambientais recomendáveis. Passivo por compensação inclui distintas subcategorias, tais como danos pessoais (mortalidade, danos corporais, tratamentos médicos, traumas físicos e mentais), prejuízo na propriedade (desvalorização de bens imobiliários, edifícios, automóveis, perda de colheita) e perdas econômicas (lucros 
perdidos, custos de aluguel provisório ou equipamentos). Os custos de compensação dependem do número e da natureza das reivindicações. Freqüentemente, custos com processos podem incluir despesas com técnicos, estudos científicos, econômicos e consultas médicas. Entretanto, responder a processos pode consumir tempo de gerentes, e requer despesas para controlar danos de imagem para a corporação. Passivo de compensação também pode envolver custos para remediação de propriedades contaminadas, bem como provisão de abastecimento de água. Por causa da lei de responsabilidade do empregador, pagamentos para compensar empregados por danos de exposição a substâncias tóxicas e perigosas, geralmente, não são determinados através de litígio contra o empregador e nem considerados um passivo ambiental.

- Indenizações punitivas - são pagamentos de multas por condutas negligentes que são impostas por lei. Diferentemente do passivo de compensação, medir indenizações punitivas não é simples para danos prolongados. Indenizações punitivas são freqüentemente mais elevadas do que os custos de compensação. Estes tendem a ser mais comuns em casos de obrigação judicial do fabricante, através de danos que foram causados por problemas com seus produtos, do que os casos de passivos ambientais. Um dos mais notáveis exemplos de indenizações punitivas são os casos de acidentes causados por navios petroleiros, como o Prestige e o Exxon Valdez.

- Danos em recursos naturais - são pagamentos por uso de recursos naturais que não constituem uma propriedade privada. Particularmente, esses recursos deveriam ser controlados pelos governos federal, estadual, municipal, internacional ou tribais. Os recursos incluem flora, fauna, terra, ar e água. O passivo pode surgir de forma acidental, bem como através do lançamento de substância no ar, água ou solo.

De acordo como o EPA (1996), existem várias técnicas para se estimar um passivo ambiental, as quais têm sido desenvolvidas e aplicadas em combinação para cada tipo de passivo ambiental.

- Técnicas atuariais (Actuarial techniques) - envolvem uma análise estatística de dados históricos ou eventos (como acidentes) ou consequiências (adversas à saúde), os quais podem conduzir a um passivo ambiental;

- Julgamento profissional (Professional judgment) - inclui uma análise baseada na experiência de engenheiros, advogados, especialistas ambientais e outros profissionais. A análise de profissionais pode ser usada para identificar as conformidades e a remediação das atividades, bem como estimar a probabilidade de acontecerem acidentes. A análise científica pode ser usada para avaliar o perigo, o transporte e destino de substâncias lançadas no ambien- te, o potencial de reação das plantas, animais, seres humanos, as propriedades dos ecossistemas, bem como um julgamento pode ser usado tanto para avaliar as bases legais do passivo quanto os danos que podem ser potencialmente recuperáveis.

- Engenharia para estimação de custos (Engineering cost estimation) - desenvolve custos identificados sistematicamente pela implementação de atividades requeridas em unidades correspondentes de custos, fatores de contingência ou outras estimações de custos paramétricos com uso de equações individuais ou agrupadas em modelos complexos, desenvolvidos através de uma análise de correlação entre custos operacionais e custos de implantação do empreendimento.

- Técnicas de análises para a decisão (Decision analysis techniques) - são usadas na construção de análises baseadas na experiência, as quais refletem incerteza na avaliação, caracterização e apresentação dos resultados na avaliação do passivo ambiental. Incertezas essas relativas à magnitude, à probabilidade e à determinação do potencial do passivo ambiental, produzindo um conjunto de passivos baseado nas suas respectivas probabilidades.

- Modelagem (Modeling) - é usada como uma alternativa ou suplemento para análises profissionais quando os dados históricos são limitados ou não-avaliáveis, e o custo ou ocorrência de valores pode ser simulado devido a muitas variáveis prováveis ou interações complexas. A modelagem é tipicamente extraída de dados disponíveis, de julgamentos de profissionais, dos relatórios de poluentes emitidos, destino, exposição e consequiências de análises técnicas estatísticas.

- Técnicas de Cenário (Scenario techniques) - são usadas para descrever e direcionar futuras situações que podem gerar passivos ambientais, assim como mudanças de requerimentos regulatórios, políticas de remediação, padrões legais para compensar danos em recursos naturais e políticas de aplicação. Poucas técnicas podem agrupar um grande número de possibilidades, representando diversas opiniões, o que inova o pensamento gerencial. A técnica de cenário desenvolve processos e envolve uma descoberta formal de análises experientes sobre futuros acidentes ambientais.

- Métodos de valoração (Valuation methods) - incluem uma variedade de papéis legais e técnicas econômicas que colocam valores legais sobre as consequiências ambientais para compensação de passivos por danos em recursos naturais. Métodos legais para avaliar danos para pessoas, suas propriedades e seus negócios, englobam práticas aceitáveis que podem ser desenvolvidas e usadas para dar valor monetário nas compensações exigidas em processos. Diferentes tipos de exigências (medo de câncer, riscos de acidentes, defeitos químicos, dor, sofrimento, 
mortalidade, entre outros) têm suas próprias aproximações de avaliação, para as quais podem variar através das jurisdições legais. Aproximações econômicas para avaliar os serviços determinados por recursos naturais que não são de propriedade privada constituem um conjunto de técnicas usadas para avaliar, direta ou indiretamente, o exercício ou não de atividades prejudiciais devido ao lançamento de poluentes.

A Agência de Proteção Ambiental (EPA) apresenta algumas ferramentas de avaliação para cada tipo de passivo relativo a danos em recursos naturais, bem como suas respectivas referências bibliográficas para situações ambientais, tais como locais com resíduos perigosos e não-perigosos, tanques de armazenamento subterrâneos e acidentes durante o transporte nas empresas de exploração de petróleo.

\section{PASSIVO AMBIENTAL NO PLANEJAMENTO DAS ORGANIZAC̄ÕES}

Segundo a EPA (1996), quando se incorpora valor monetário de passivo ambiental no planejamento, na tomada de decisões e operações, as organizações precisam expressar ou estimar a magnitude dos valores em função do momento, da probabilidade e das incertezas associadas com futuras despesas. A seguir será apresentada cada uma dessas funções relacionadas pela EPA.

\section{Momento}

Por definição, todo passivo ambiental envolve custos futuros. Uma aproximação comum para estimar pagamentos futuros é calcular seus valores líquidos no presente. Isso requer uma estimação da magnitude e determinação do tempo de futuras despesas. Em alguns casos, as despesas com passivos de remediações e conformidades podem ocorrer entre três e cinco anos. Cada passivo, entretanto, também pode não ser cobrado em determinado momento no futuro. Passivos de conformidade e remediação também podem ocorrer ao longo dos anos na natureza. Na maioria dos casos, as regulações requerem que as companhias respondam por passivos para no mínimo três anos após o fechamento delas por aparatos de disposição de resíduos. Para remediar fontes de água em alguns locais, podem-se exigir cinqüenta ou mais anos de remoção e tratamento. Dessa forma, os passivos podem ser exigidos para pagamentos ao longo do tempo, em oposição a uma soma de gastos (EPA, 1996).

Passivos por compensação de danos em recursos naturais podem aparecer num momento próximo ou num tempo futuro, ou seja, são passíveis de ocorrer a qualquer momento, como no caso dos acidentes. Reciprocamente, para lançamentos de poluentes no presente ou futuro, a exposição de pessoas e propriedades pode continuar existindo por muitos anos antes de qualquer aspecto adverso ao ambiente ou efeitos à saúde, como muitas formas de câncer, que são manifestadas somente em períodos latentes num futuro. Dessa forma, compensação por declaração de danos pode passar muitos anos para se materializar após o uso ou lançamento de resíduos químicos.

Segundo a EPA (1996), para entender melhor o potencial da determinação do tempo de passivo ambiental é importante distinguir entre as seguintes situações:

a) Custos futuros que não podem ser evitados ou prevenidos, devido a eventos em locais já ocupados;

b) Custos futuros que podem ser evitados ou prevenidos.

A maioria dos estudos contábeis que discutem o passivo ambiental refere-se à primeira categoria, enquanto a maioria dos artigos de gerenciamento de risco e planejamento aplica-se à segunda categoria.

Os termos de passivo "retrospectivo" e "prospectivo" são usados somente como rótulo para diferenciar essas duas situações.

A determinação do tempo do passivo ambiental tem um peso importante nas tomadas de decisões para reduzir os custos ou prevenir esses passivos. Embora existam algumas formas para gerenciar custos futuros decorrentes de atividades e poluição já ocorridas, diferentes tipos de negócios feitos agora e no futuro podem afetar uma companhia devido a diferentes passivos ambientais existentes.

$\mathrm{Na}$ avaliação do passivo ambiental, pode ser útil distinguir três itens:

a) Passivo ou potencial de passivo devido a atividades realizadas no passado;

b) Passivo ou potencial de passivo devido a atividades realizadas no presente;

c) Potencial de passivo devido a atividades que serão realizadas no futuro.

As últimas duas categorias representam oportunidades para uma companhia prevenir os custos com passivos ambientais. Levando em consideração os custos potenciais com passivos ambientais à frente das decisões de negócios, gerentes e contadores podem realizar benefícios financeiros e alterar práticas correntes ou evitar novas atividades que possam ocasionar passivos ambientais (EPA, 1996).

\section{Probabilidade}

Gestores precisam considerar a probabilidade de ocorrência do potencial de passivo ambiental como um peso para estimar os valores monetários frente ao potencial de custos, como uma opção do gerenciamento para prevenir 
(ou reduzir) a probabilidade de ocorrência desses passivos. Uma aproximação comum para avaliar um potencial de passivo ambiental é calcular seus valores esperados, que correspondem aos produtos das magnitudes previstas e suas respectivas probabilidades de ocorrência. Dessa forma, o valor monetário é estimado para ponderar a probabilidade de uma futura despesa ser feita. Por exemplo, se um potencial de passivo ambiental foi estimado em $\mathrm{R} \$ 1.000 .000,00$ (um milhão de reais) e a sua probabilidade de ocorrência é de $10 \%$, então o valor esperado desse passivo é de $\mathrm{R} \$ 100.000,00$ (cem mil reais). A probabilidade de uma futura despesa ser feita depende da certeza ou não do potencial de ocorrência do passivo, ou, alternativamente, depende da incerteza de ocorrência ou não de um ou mais eventos futuros. O que dificulta a avaliação da probabilidade de custos do passivo ambiental dos gestores é a inclusão de questões relativas à ocorrência de fatos (Ocorrerão vazamentos em carros tanques?; Haverá crianças expostas a uma determinada substância?; Haverá danos a elas?; Haverá fontes de águas contaminadas?) e a questões legais (Essa lei se aplica a este caso?; Haverá uma exigência para remediar essa propriedade?; São essas reivindicações de danos compensáveis?; Quem é ou será legalmente responsável?). Assim, estimar a probabilidade de um potencial de passivo pode exigir análises de engenharia, estatísticas, legais e até julgamento. As perguntas factuais e legais podem ser difíceis de ser respondidas, particularmente quando os gerentes estão fazendo projeções para tomada de decisões, embora, com o tempo, a partir de dados mais confiáveis, as perguntas factuais fiquem mais fáceis de trabalhar e os precedentes legais mais fáceis de serem respondidos (EPA, 1996).

\section{a) Probabilidade para passivo de conformidade}

A probabilidade de responsabilidades da conformidade de todas os passivos ambientais discutidos aqui tem um nível baixo de incerteza associada. Se uma lei se aplicar a uma situação, a uma atividade, ou a uma substância, as despesas a vir na conformidade devem ser feitas por uma data especificada. Conseqüentemente, não pode haver nenhuma necessidade de ajustar o custo estimado de conformidade para refletir a probabilidade de ocorrência do passivo. Por exemplo, os regulamentos requerem que aqueles que causem danos na superfície por resíduos perigosos devem, em algum momento do futuro, corrigi-los obrigatoriamente. Não há nenhuma maneira de evitar a obrigação de reparar danos. Entretanto, se a correção não se encontrar "dentro dos padrões adequados", então será exigida uma nova correção. Essa exigência será realizada de acordo com os procedimentos adequados de correção. Nesse exemplo, dada a certeza da probabilidade de correção dos danos, seu custo estimado não necessita ser ajustado, mas o custo potencial de refazer os reparos pode ser ajustado para refletir a probabilidade de que novos custos de correções estarão incluídos. Um outro exemplo para evitar as exigências de relatórios de controle de emissões, que se aplicarão aos usuários que lançam uma determinada substância na camada de ozônio, é a empresa procurar uma substância alternativa (ou um processo alternativo) que não seja regulamentada. Esse é um exemplo de uma obrigação de conformidade que não apresenta contingência para um evento futuro, mas, particularmente, torna-se evitável, uma vez que o uso não pode ser aplicado a suspensão da substância. Nesse exemplo, dado que as despesas futuras de conformidade serão certamente incorridas, seria impróprio ajustar o custo de conformidade estimado para a probabilidade. O custo de conformidade deve ser considerado ao avaliar práticas alternativas (EPA, 1996).

\section{b) Probabilidade do potencial para passivo de remediação}

O potencial do passivo de remediação para futuras contaminações possui diferentes tipos de incertezas associadas. Potencial de incertezas factuais pode ser incluído, no mínimo, se houver uma poluição ou ameaça de poluição para o ambiente, através de transporte e/ou descoberta de poluição. Dependendo da situação, o potencial legal de incertezas será incluído se existir uma obrigação para remediar e se esse passivo for comum a outros. O segundo contingente pode ser relevante para uma companhia que deposita seus resíduos no meio comercial e que também aceita resíduos de outros. Nessas situações, a magnitude do valor monetário estimado para o potencial do passivo de remediação será ajustada para refletir sob a probabilidade baseada na proporcionalidade de qualquer passivo, para cada uma das companhias legalmente responsáveis. Entretanto, pode ser apropriado observar o potencial do passivo de remediação para futuras contaminações dadas como certas, para práticas de armazenamento subterrâneo de produtos de petróleo ou outras substâncias, tais como a injeção subterrânea de resíduos, o aterro de resíduos sólidos e resíduos líquidos na superfície. No decorrer do tempo, gotejamentos de contaminantes podem aumentar facilmente. Um gerenciamento preventivo pode tratar cada despesa de remediação futura como certeza por não ajustar a magnitude do potencial de passivo às suas probabilidades de ocorrência. Isso fornecerá aos gerentes um grande incentivo para encontrar alternativas para o uso de tal prática, por causa de um alto valor monetário que será associado com o potencial do passivo (EPA, 1996). 


\section{c) Probabilidade para passivo de compensação}

A probabilidade de um passivo de compensação geralmente não é considerada como uma certeza, devido a muitos obstáculos factuais e legais que devem ser cruzados antes da ocorrência do passivo. Assim como o passivo de remediação, o passivo de compensação pode depender de fatores como a existência de poluição (seja acidental, periódica ou contínua), da exposição de seres humanos ou de suas propriedades às poluições, e dos códigos penais prevalecentes. Para que uma reivindicação de compensação se transforme numa obrigação de compensação, os políticos devem adotar um estabelecimento para pagamento ou a corte judicial deve encontrar uma maneira de satisfazer a reivindicação para uma variedade de experiências legais e factuais. Na avaliação de tal potencial do passivo, as companhias podem ajustar suas estimações de custos do passivo para refletir suas probabilidades de ocorrência. Por exemplo, o valor esperado do potencial do passivo de compensação de $\mathrm{R} \$ 10$ milhões com probabilidade de um por cento é de $\mathrm{R} \$$ 100.000,00 (cem mil reais). Alternativamente, enquanto uma companhia - em seu planejamento e tomada de decisão - pôde escolher tratar determinados passivos de remediação para uma contaminação futura (por exemplo, do armazenamento ou da eliminação subterrânea de substâncias) como certezas eventuais, uma outra companhia, com atitude conservadora por parte da gerência, pôde escolher tratar os passivos de compensação selecionados (por exemplo, monitoração médica para pessoas expostas às poluições regulares de poluentes perigosos do ar), enquanto o certo seria buscar incentivos para desenvolver práticas alternativas que eliminariam ou reduziriam tais poluições regulares (EPA, 1996).

\section{d) Probabilidade para passivo de multas e penalidades por não-conformidades}

Penalidades e multas são duplamente incertas. Primeiramente, a maioria das companhias considera as nãoconformidades eventos incertos e improváveis, a menos que uma firma tenha uma política incorporada para desprezar deliberadamente as leis ambientais. A não-conformidade pode ser comparada às poluições acidentais nenhum acidente é pretendido explicitamente, mas a gerência pode influenciar em algum grau nas probabilidades de que esses eventos venham a ocorrer (por exemplo, investindo em treinamentos e tecnologia). Em segundo lugar, as penalidades e multas são provocadas somente no momento da descoberta da não-conformidade (através de uma inspeção oficial ou do requerimento de informações). Assim, o valor do potencial do passivo devido às multas e penalidades pode ser ajustado para: i) Refletir a probabilidade de não estar em conformidade; ii) Refletir a probabilidade da descoberta de não estar em conformidade.

Se uma companhia, entretanto, prefere basear seu planejamento e a tomada de decisão na presunção de que toda não-conformidade será descoberta, ela escolherá não fazer nenhum ajuste para a probabilidade da descoberta (EPA, 1996).

\section{e) Probabilidade de passivo para danos em recursos naturais}

Danos em recursos naturais que resultam em poluições acidentais, tais como derramamentos durante o transporte, são eventos improváveis na natureza. Similarmente, os danos em recursos naturais causados por poluição de substâncias perigosas (devido aos incêndios, às explosões ou aos terremotos) são eventos incomuns. Assim, pode ser apropriado ajustar o valor potencial de tais passivos por danos em recursos naturais para estimar a probabilidade de suas ocorrências. $O$ passivo por danos em recursos naturais também é novo e as reivindicações são prováveis de ser litigadas, talvez devido a futuras alterações dos recursos naturais que causam grandes impactos. Entretanto, danos em recursos naturais podem ser causados por lançamentos regulares de poluentes no meio ambiente. Embora tais danos nos recursos naturais não sejam intencionais, as poluições por si próprias não são acidentais nesses casos.

Em caso de poluições intencionais, uma companhia pode decidir estimar o passivo para os danos de recursos naturais como resultado certo de suas práticas, reconhecendo os custos como inteiramente evitáveis quanto às práticas alternativas de avaliação da prevenção e do controle da poluição, isto é, nenhum ajuste para a probabilidade (EPA, 1996).

\section{Incerteza}

As estimativas ou as projeções dos custos futuros têm incertezas inevitáveis. Podem existir incertezas a respeito (1) da magnitude do valor, (2) da probabilidade da ocorrência, e/ou (3) do tempo de um passivo. Essas incertezas podem ser decorrentes da variabilidade inerente ou de uma falta de informação. Diversas das estimações de passivos podem desenvolver resultados de maneira que as incertezas se tornem mais transparentes. Por exemplo, os níveis estimados de custos do passivo podem ser emparelhados com suas respectivas probabilidades de ocorrência, isto é, sendo denominada a distribuição de probabilidade. O desenvolvimento de uma distribuição de probabilidade fornece informações sobre o potencial de custos do passivo e facilita o cálculo "do 
valor esperado" dos custos de um passivo. Tal distribuição de probabilidade pode facilmente ser convertida "em uma distribuição de freqüência acumulada", de forma a indicar que a probabilidade dos custos do passivo estará acima ou abaixo de um dado valor. Por exemplo, para estimar as probabilidades do potencial para poluições acidentais e o custo resultante de remediação, as técnicas de análise para a decisão podem ser utilizadas como um recurso para avaliar as probabilidades dos custos de remediação, excedendo vários níveis em dólares. Passivos de compensação têm sido tratados de forma similar. Uma aproximação é também aplicável a passivos de multas e penalidades. Essas aproximações estatísticas fornecem mais informações do que um único custo. Os gerentes podem selecionar seus próprios níveis de adversidade para os riscos de tais distribuições (EPA, 1996).

\section{CONSIDERAC̣̃̃ES FINAIS}

O passivo ambiental está intimamente relacionado a custos e ao desempenho ambiental e merece atenção dos gestores ambientais para que possam compreender sua importância e implementá-lo na política ambiental como uma ferramenta de gestão na produção de bens.

Antecipar as questões ambientais, a princípio, é uma estratégia que os gestores empresariais necessitam adotar como prevenção das fiscalizações dos órgãos ambientais. As empresas precisam implantar sistemas de proteção ambiental, independentemente das pressões do mercado como uma forma de evitar prejuízos maiores no futuro.
A produção objetiva a satisfação das necessidades básicas para uma permanência digna, por outro lado, a natureza infelizmente não pode esperar pela livre iniciativa dos gestores empresariais, pois a velha idéia de que os recursos naturais são inesgotáveis está ultrapassada e está cada vez mais globalizada a preocupação com a racionalização dos recursos naturais para o desenvolvimento sustentável.

A divulgação das técnicas de passivo ambiental se faz necessária para formar uma consciência dos atuais e futuros gestores na implementação de técnicas que garantam a saúde da empresa e do meio ambiente. Os gestores dos setores público e privado devem assumir a responsabilidade e procurar quantificar os passivos das organizações para conhecer suas obrigações em termos financeiros com o meio ambiente e com terceiros prejudicados de alguma forma por impactos sofridos. No caso do setor de exploração de petróleo, tal iniciativa é pertinente.

A indústria de exploração de petróleo é uma das que sofrem enormes quantidades de penalidades por danos causados ao meio ambiente, principalmente nos setores de exploração, transporte e armazenagem, necessitando de ferramentas para estimar o passivo ambiental tanto para danos existentes quanto para previsão de possíveis acidentes. A adoção de atitudes responsáveis na resolução de problemas ambientais para garantir a sobrevivência da fauna e da flora na atualidade, conseqüentemente das futuras gerações, reflete uma postura pró-ativa e estratégica das organizações.

\section{Artigo recebido em 05/09/2003 Aprovado para publicação em 09/01/2004}

\section{- Referências}

ANTONIUS, P. A. J. A exploração dos recursos naturais face a sustentabilidade e gestão ambiental: uma reflexão teórico-conceitual. Belém: NAEA, 1999

ÁVILA, Carlos. Uma solução Inteligente para Resíduos Industriais. Meio Ambiente Industrial, n. 35, ano VI, p. $90-91$, mar./abr./2002.

AZUAGA, D. Danos ambientais causados por veículos leves no Brasil. Rio de Janeiro, 2000. 168p. Dissertação (M.sc, Programa de Planejamento Energético) - COPPE, Universidade Federal do Rio de Janeiro.

CARVALHO, L. Nelson; RIBEIRO, Maisa de Souza. A posição das instituições frente ao problema das agressões ecológicas. Trabalho apresentado no IX semana de Contabilidade do banco Central do Brasil, FEA/USP - SP, 9 a 10/11/2000.
CLARO, P. B. O; MAFRA, F. L. N; CLARO, D. P. Consciência ou Imposição: um estudo sobre os fatores condicionantes do comportamento ambiental de uma organização rural Holandesa. Caderno de pesquisas em Administração, São Paulo, v. 8, n. 3, jul./set. 2001.

EPA (US Environmental Protection Agency). Valuing potential environmental liabilities for managerial decision-marking: a review of available techniques". Publication 742-R-96003; Washington DC: EPA, 1996.

GAldino, C. A. B, et al. Passivo ambiental das organizações: uma abordagem teórica sobre avaliação de custos e danos ambientais no setor de exploração de petróleo. XXII ENEGEP Curitiba, Paraná de 22 a 25 de out. 2002.
HOLLINS, Margaret and Percy, S. Environmental liability for contaminated land - towards a European consensus. Land Use Policy, v. 15 , i.2, April 1998, p. 119-133.

JIN, Di; POWELL, Hauke L. Kite, On the optimal environmental liability limit for marine oil transport. Marine Police, March 1999, p. 77-100.

MACHADO, V. M. Estimativa da Contribuição do Setor Petróleo ao Produto Interno Bruto do Brasil. Superintendência de Estudos Técnicos - ANP, 2002.

PETROBRÁS BRASILEIRO S. A. PETROBRÁS. Análise financeira e demonstrações contábeis, 2001.
PHILLIPS, John H. Environmental liability after the corporation dies: the difference between "dead" and "dead and burried". Metal Finishing, v. 98, i. 12, December 2000, p. 58-60.

RIBEIRO, M. S; LISBOA, L. P. Passivo Ambiental. Trabalho apresentado no XVI Congresso Brasileiro de Contabilidade, Goiânia - GO, 15 a 20/10/2000.

RIBEIRO, Maisa de Souza Ribeiro; SOUSA, Ana Lucia Bertoli. Passivo ambiental: estudo de caso do Petróleo Brasileiro S.A - Petrobrás. A repercussão ambiental dos acidentes ocorridos, nas demonstrações contábeis. XXVII ENANPAD, Aidaia/SP de 20 a 24/09/ 2003. 